DOI: 10.12731/2070-7568-2017-2-24-44

УДК 349.444

\title{
ПРАВОСУБЪЕКТНАЯ ПРЕДПОСЫЛКА И ОСНОВАНИЕ ПРАВООТНОШЕНИЯ ПО НАЙМУ СЛУЖЕБНОГО ЖИЛОГО ПОМЕЩЕНИЯ
}

\section{Папушина Н.Ю.}

Настоящая статья посвящена вопросам определения правосубъектной предпосылки и основания правоотношения по найму служебного жилого помещения. Автором поставлена цель конкретизации условий правосубъектной предпосылки и определения особенностей основания правоотношения по найму служебного жилого помещцения, поскольку ответы на эти вопросы позволяют с достоверностью определить законность занятия лицом такого жилья, что, в свою очередь, лежит в основе вынесения судом справедливого и обоснованного решения как по искам о предоставлении служебных квартир, так и по искам об их освобождении.

По мнению автора, условия правосубъектной предпосылки определяются, в первую очередь, характером работы или службы гражданина, которые предполагают возможность его привлечения к исполнению своих обязанностей во внерабочее время. Это исключает возможность предоставления служебных жильх помещений лиияам, характер труда которых не отвечает таким условиям.

Основание же правоотношения по найму служебного жилого помещчения или правообразующий юридический состав образуют несколько самостоятельных правоотношений, из которых одно может быть поименовано как административно-организационное (им охватываются действия уполномоченных органов и лии по включению жилого помещчения в состав специиализированного жилищьного фонда), а второе как учетно-организачионное, охватывающее действия по принятию лица на учет нуждающихся, принятию решения о предоставлении служебного жилья. Кроме того 
самостоятельным элементом правообразующего юридического состава выступает договор найма служебного жилого помещуения.

Цель: конкретизация условий правосубъектной предпосылки и элементов юридико-фактического основания правоотношения по найму служебного жилого помещуения.

Метод или методология работь: при написании статьи автором использовались исторический, формально-юридический, $а$ также сравнительно-правовой методь исследования.

Результаты: автором описаны и конкретизированы условия правосубъектной предпосылки, а также элементы правообразуюшего юридического состава (юридико-фактического основания) правоотношения по найму служебного жилого помещения.

Область применения результатов: полученные результаты могут применяться как при дальнеймем доктринальном изучении отномений по найму служебных жильх помещзений, так и при разрешении конкретных жилищных споров, касающцихя правомерности предоставления служебных жильх помещуений и прожсивания в них

Ключевые слова: служебное жилое помещуение; договор найма служебного жилого помещтения; правосубъектная предпосылка; основание жилищного правоотношения найма служебного жилого помещуения; предоставление служебного жилого помещуения; правомерность занятия служебного жилого помещуения.

\section{PERSONABLE PREREQUISITE AND THE BASIS OF LEGAL RELATIONSHIP ON TENANCY OF EMPLOYEES}

\section{Papushina N.Yu.}

The article examines issues of definition of a personable prerequisite and the basis of legal relationship on tenancy of employees. The author set specification of terms of a personable prerequisite and definition of features of the basis of legal relationship on tenancy of employees as the main goal whereas these answers allow to define trustworthy legalness of 
person's occupation of such housing that in its turn is the cornerstone of rendering of reasonable and justified judicial decision by the court as in claims for granting corporate apartments, and in claims for relief them.

According to the author, terms of a personable prerequisite are defined first of all by a kind of a work or services of the citizen which assume a possibility of involvement with working in off-duty hours. It excludes a possibility of granting tenancy for employees to people whose nature of work does not answer such terms.

The legal relationship basis on tenancy of employees or the right-conferring set of facts form several independent legal relationships from which one can be named as administrative and organizational (it covers actions of competent authorities and persons for including housing into the housing fund), and second can be invoice and organizational, covering actions for acceptance of the person on the accounting of persons in need, to making decision on granting office housing, and also the conclusion of the employment contract of office premises.

Object: a specification of terms of a personal prerequisite and elements of the legal and factual basis of legal relationship on tenancy of employees.

Method of work: author used historical, technical, and also comparative and comparative methods of a research.

Results: author described and concretized terms of a personable prerequisite and elements of the right-conferring legal structure of a legal relationship on tenancy for employees.

Range of use: received results can be applied both as at further doctrinal studying of the relations on tenancy for employees and as at permission of a concrete housing disputes concerning legitimacy of tenancy for employees.

Keywords: tenancy for employees; residential lease agreement for employees; personable prerequisite; basis of legal relationship of tenancy for employees; housing; legitimacy of an occupation of housing.

Правовая категория «служебное жилое помещение» известна отечественному праву еще с первой половины XX столетия. Не- 
смотря на смену экономических эпох, предоставление и пользование служебными жилыми помещениями претерпело не столь значительные изменения по сравнению с правовым режимом жилых помещений социального найма. Тем интереснее представляется анализ правоотношений по найму служебного жилья через призму предпосылок их возникновения и юридико-фактическое основание, которые с течением времени, по сути, принципиально не изменились, а лишь в значительной степени законодательно оформились, условно говоря, «выкристаллизовались» под воздействием объективных факторов общественной жизни.

Вне всякого сомнения, жилищное правоотношение по предоставлению и пользованию служебными жилыми помещениями не является «застывшим» [10], лишенным динамики правовым явлением. Оно подвергается изменению, как под влиянием течения общественной жизни, так и следующего за социальными трансформациями законодательного регулирования, устанавливающего определенные модели взаимодействия сторон такого правоотношения.

Очевидно, что перед законодателем не стоит задача сконструировать несуществующую модель правовых отношений на некое возможное будущее общественное устройство, которое, впрочем, вопреки его задумке может никогда и не испытать потребности в предложенном правовом регулировании. Напротив, законодательная деятельность должна ответить на вопрос о нахождении оптимальных путей удовлетворения тех общественных потребностей, которые диктуются самим укладом жизни, во многом определяемом складывающимися экономическими отношениями.

Именно потребности, по меткому замечанию О.А. Красавчикова, создают для человека объективную необходимость вступления в определенные общественные отношения, регламентированные правом [6, с. 10]. И если потребность в обладании определенным благом, может рассматриваться в качестве материальной предпосылки правоотношения, то она в любом случае не в силах продолжить самостоятельное движение, реализоваться в действиях человека вне наличия иных предпосылок: нормативной и право- 
субъектной, из которых первая представляет собой закрепленную в законе модель поведения (норму права), а вторая, как определяет ее О.А. Красавчиков, способность лица к участию в гражданскоправовых отношениях [7, с. 83]. Иначе говоря, правосубъектную предпосылку можно определить, как потенциальную возможность для лица обрести благо и реализацию такой возможности его действиями через установленную законом модель поведения ради удовлетворения той или иной потребности.

Единство материальной, нормативной и правосубъектной предпосылок служит основой для возможности возникновения конкретного правоотношения. На возможность возникновения правоотношения только при наличии определенных предпосылок указывал Ю.К. Толстой $[9$, с. 3]. Такое утверждение вполне справедливо и применительно к жилищному правоотношению служебного найма.

Однако сами по себе предпосылки, даже взятые в единстве, не приводят общественное отношение в движение. Представляется очевидным, что для начала любого движения (в том числе, если мы ведем речь о движении правоотношения) нужна отправная точка, основание. Применительно к общественному отношению, урегулированному нормами права, в качестве такой «точки опоры» выступает юридико-фактическое основание. Так, О.А. Красавчиков определял юридико-фактическое основание правоотношения как факты реальной действительности, с которыми нормы права связывают возникновение, изменение или прекращение соответствующих прав и обязанностей правосубъектного лица [7, с. 83].

Следовательно, в качестве юридико-фактического основания жилищного правоотношения выступают соответствующие юридические факты. Юридические факты при этом следует рассматривать как «объективно существующие явления действительности» [5, с. 93], зависящие не от нормы права, а от складывающихся общественных отношений, т.е. в качестве фактического основания. Вместе с тем, даже если эти явления находятся вне воздействия воли человека, именно в результате их фиксации в норме права и придания им юридического значения они приобретают качества 
юридического основания. Применительно к жилищному правоотношению М.В. Бандо отметил, что закон, во-первых, констатирует правосубъектную предпосылку и юридико-фактическое основание такого правоотношения, а во-вторых, задает модель основных его элементов [2, с. 12].

Поэтому, анализируя правосубъектную предпосылку и юридико-фактическое основание отношений по найму служебного жилого помещения, необходимо определить, как законодатель, описывая их конструкцию, отвечает на вопросы о том, кто имеет право на предоставление ему служебного жилого помещения, и что является основанием для занятия такого помещения и пользования им.

Отвечая на вопрос о правосубъектной предпосылке, необходимо очертить круг лиц, обладающих правом на предоставление служебного жилого помещения, определить, в силу обладания какими «качествами» или «свойствами» эти лица вправе претендовать на занятие служебного жилого помещения. Для чего будет уместно сделать небольшой исторический экскурс в ранее имевшее место правовое регулирование категории «служебное жилое помещение».

Так, согласно Гражданскому кодексу РСФСР 1922 года (в который для этой цели в 1926 году была дополнительно введена статья 171-а) [18] допускалось выселение в судебном порядке лиц, прекративших трудовой договор, заключенный под условием предоставления нанявшему специального жилого помещения. При этом к специальным жилым помещениям законодатель отнес жилые помещения, специально предоставленные для проживания рабочих и служащих, а также помещения, расположенные в служебных зданиях и предоставленные работнику в связи с трудовыми отношениями.

В дальнейшем понятие «служебное жилое помещение» было закреплено в Гражданском кодексе РСФСР 1964 года [16], где в статье 297 установлено, что служебные жилые помещения предоставляются гражданам для проживания по месту работы или в служебном здании в связи с характером трудовых отношений.

Таким образом, законодатель сохранил общий подход к определению служебного жилья, указав, что такие жилые помещения мо- 
гут быть предоставлены именно работникам, исключительно временно (на период работы) и только при условии особого характера трудовых отношений, предполагающих необходимость проживания в непосредственной близости от места работы.

Аналогичное регулирование отношений по занятию служебных жилых помещений было дано и в статьях 101-102 Жилищного кодекса РСФСР 1983 года [17]. Согласно положениям данного Кодекса служебные жилые помещения предназначались для их заселения гражданами, которые в связи с характером трудовых отношений должны проживать по месту работы или вблизи от него. Проживание в служебных жилых помещениях носило срочный характер и определялось сроком трудовых отношений (статья 106 Жилищного кодекса РСФСР).

В настоящее время под служебным жилым помещением действующий Жилищный кодекс Российской Федерации 2004 года [12] понимает жилое помещение, относящееся к специализированному жилищному фонду, формирующемуся из жилых помещений, находящихся в домах государственного и муниципального жилищного фондов.

К лицам, обладающим правом на предоставление служебного жилого помещения, Жилищный кодекс Российской Федерации относит граждан, которым в связи с характером их трудовых отношений с органом государственной власти, органом местного самоуправления, государственным или муниципальным унитарным предприятием, государственным или муниципальным учреждением, в связи с прохождением службы, в связи с назначением на государственную должность Российской Федерации или государственную должность субъекта Российской Федерации либо в связи с избранием на выборные должности в органы государственной власти или органы местного самоуправления на соответствующий период работы, службы или исполнения обязанностей по должности должны предоставляться служебные жилые помещения (статьи 93, 104 Жилищного кодекса РФ).

Вышеприведённые нормативные положения позволяют сделать вывод, что исторически сложилось такое понимание и регулирова- 
ние найма служебного жилья, которое позволяет определить правосубъектную предпосылку правоотношения по предоставлению и пользованию служебным жилым помещением через совокупность следующих условий.

Во-первых, нанимателем по договору служебного найма может выступать только гражданин, причем состоящий в трудовых или служебных правоотношениях. При этом, по мнению автора, употребление термина «гражданин» в данном случае допущено применительно к понятию «физическое лицо», а не к понятию «гражданин государства». Этот вывод напрашивается из анализа сохранивших свое действие нормативно-правовых актов Совета Министров РСФСР, согласно которым правом на предоставление служебного жилого помещения до настоящего времени обладают, в том числе, почтальоны, работники конезаводов, слесари, дворники и техники-смотрители. Очевидно, что занятие указанных должностей возможно не только гражданами Российской Федерации, но и иностранными гражданами, а также лицами без гражданства. В силу чего сужение круга лиц, которые вправе (при определенных условиях) претендовать на занятие служебного жилого помещения, исключительно по признаку их принадлежности к гражданству Российской Федерации вряд ли оправданно.

В качестве следующего условия правосубъектной предпосылки законодателем определен характер работы или службы. Это вполне исторически оправданно, поскольку само появление служебных жилых помещений было продиктовано именно характером труда работника, который должен быть задействован в обслуживании зданий или помещений по месту своего проживания или в непосредственной близости от него.

Хотя в настоящее время такой критерий как необходимость проживания работника непосредственно по месту работы или в непосредственной близости от него законодателем не закрепляется, следует, вне всякого сомнения, согласиться с П.В. Крашенинниковым, вводящим такое условие в качестве обязательного элемента в понятие «служебное жилое помещение» [8]. 
Представляется, что с учетом категорий работников, для которых законодательно закреплена возможность предоставления служебного жилого помещения, характер осуществляемой ими трудовой или служебной функции предполагает возможность (при возникновении соответствующей необходимости) осуществления трудовой или служебной функции в условиях ненормированного рабочего дня, а равно незамедлительного прибытия к месту работы или службы [4]. Это, в свою очередь, означает, что работник не должен затрачивать значительный период времени для проезда к месту работы (службы) от места жительства, что предполагает предоставление служебного жилого помещения в пределах как минимум соответствующего населенного пункта, а при возможности в непосредственной близости от места работы или службы.

Необходимо отметить, что законодатель в действующем Жилищном кодексе РФ прямо указал на нуждаемость в жилом помещении, как на одно из условий правосубъектной предпосылки. И хотя предоставление служебного жилого помещения выступает одной из форм обеспечения граждан жилыми помещениями, речь все же идет не об удовлетворении потребности в жилье как таковой. В данном случае под нуждаемостью подразумевается необходимость обеспечения близости нахождения работника, непосредственно к месту выполняемой им работы или службы, которое преследует цель наиболее эффективного выполнения работником своей трудовой функции [11], а не предоставления жилья как самостоятельного блага. Поэтому ключевым в определении нуждаемости в служебном жилом помещении будет не вопрос о наличии у лица жилого помещения для проживания как такового, а вопрос о наличии у него жилого помещения в местности, где расположено место его работы или службы.

Следовательно, вопрос о нуждаемости в служебном жилом помещении в отличие от правил ст. 49 Жилищного кодекса РФ может решаться не только органами местного самоуправления, но и иными лицами, в ведении которых находится соответствующий жилищный фонд. По мнению автора, к ним могут относиться лица, 
перечисленные в статье 93 Жилищного кодекса РФ, что не исключает как возможность ведения учета нуждающихся в служебных жилых помещениях, к примеру, непосредственно государственным унитарным предприятием, так и решение таким предприятием вопроса о предоставлении служебного жилого помещения нуждающемуся в нем работнику. Однако такое предоставление в любом случае должно осуществляться с учетом положений статьи 104 Жилищного кодекса РФ, т.е. только теми лицами, в ведении которых находится соответствующий муниципальный или государственный жилищный фонд, и при этом обладающих правом реализации от имени собственника соответствующих полномочий, в том числе правом распоряжения жилищным фондом.

Справедливости ради следует отметить, что законодателем предусмотрены и такие случаи, когда распоряжение соответствующим жилищным фондом производится не только его не собственником, но даже и лицом, не имеющим какого-либо имущественного права в отношении служебных жилых помещений. К примеру, положения пункта 5 статьи 15 Федерального закона 27 мая 1998 года № 76-Ф3 «О статусе военнослужащих» [13], закрепляющие право военнослужащих на занятие освобождающихся жилых помещений, ранее занимаемых военнослужащими и совместно проживающими с ними членами семей.

На это обстоятельство, в частности, указано в Определении Конституционного Суда Российской Федерации от 25 декабря 2003 года № 453-О «Об отказе в принятии к рассмотрению жалобы Администрации муниципального образования «Сертолово» Ленинградской области на нарушение конституционных прав и свобод пунктом 5 статьи 15 Федерального закона «О статусе военнослужащих» [19]. Хотя в самом решении Конституционного Суда РФ речь идет о предоставлении жилого помещения на условиях социального найма, суды учитывают его нормативное значение и в тех случаях, когда речь идет о служебных жилых помещениях, распределение которых осуществляется региональными управлениями Министерства обороны РФ. Так, правоприменительной практике [21] известны 
случаи, когда служебные жилые помещения предоставлялись военнослужащим в обход воли муниципальных образований структурным подразделением Министерства обороны РФ или иным лицом, осуществляющим функции обеспечения военнослужащих жилыми помещениями, даже и в том случае, когда такие жилые помещения являлись муниципальной собственностью. При разрешении спора такое предоставление признавалось судами правомерным со ссылкой на положения пункта 5 статьи 15 Федерального закона 27 мая 1998 года № 76-Ф3 «О статусе военнослужащих» и нормативное толкование, данное в Определении Конституционного Суда Российской Федерации от 25 декабря 2003 года № 453-О.

Анализируя правосубъектную предпосылку для занятия служебного жилого помещения, необходимо отметить, что условие о малоимущности гражданина не имеет значения, поскольку, как уже указывалось автором выше, предоставление служебного жилого помещения не преследует цель удовлетворения потребности в жилом помещении как таковой. Это означает, что гражданин на период выполнения им работы, прохождения службы или пребывания на государственной (выборной) должности обеспечивается условиями, которые позволяют ему в полной мере осуществлять свою специфическую трудовую или служебную функцию. В силу чего предоставление служебного жилого помещения, в свою очередь, не влечет каких-либо правовых последствий относительно реализации права лица, которому такое помещение предоставлено, на предоставление жилого помещения на условиях социального найма.

Обобщая вышеизложенное, можно утверждать, что исторически сложилось такое правовое регулирование, которое предполагает, что право на предоставление служебного жилого помещения имеет физическое лицо, работа, служба или осуществление должностных обязанностей на государственной (выборной) должности которого имеют специфический характер, предопределяющий неопределенную продолжительность рабочего дня и необходимость немедленного прибытия к месту работы или службы. При этом данное лицо 
в силу специфики своей работы или службы должно нуждаться в жилом помещении именно для целей осуществления возложенных на него должностных обязанностей в непосредственной близости от места работы или службы, но в любом случае в пределах соответствующего населенного пункта.

Автор полагает, что совокупность условий, описывающих круг лиц, обладающих правом на предоставление служебного жилого помещения, и определяет содержание правосубъектной предпосылки для возникновения правоотношений по найму служебного жилого помещения. Кроме того, по мнению автора, существует тесная связь между правосубъектной предпосылкой и тем, по инициативе какого лица начинается движение правоотношения. Иначе говоря, правосубъектная предпосылка описывает способность того лица, чьи воля и действия приводят в движение правоотношение, хотя материальная предпосылка как потребность в определенном благе может наличествовать у обеих сторон правоотношения. Причем, не всегда материальная предпосылка у сторон правоотношения лежит в одной и той же сфере. К примеру, потребность конкретного офицера в служебном жилом помещении определяется отсутствием у него жилья по месту прохождения службы. В то время как потребность государства (в широком смысле), принявшего его на военную службу, лежит отнюдь не сфере обеспечения лица жилым помещением. Материальная предпосылка (цель) вступления в правоотношения по найму служебного жилого помещения со стороны государства заключается в обеспечении безопасности, охране государственного суверенитета и правопорядка, которая достигается путем привлечения к осуществлению такой функции наиболее профессионально подготовленных лиц.

Однако, как указывает Е.С. Данилова, предпосылки образуют лишь потенциальную возможность динамики правоотношения, однако его претворение в жизнь невозможно без юридико-фактического основания [3], которое, по мнению автора настоящей статьи, с учетом комплексного характера жилищных правоотношений предпочтительно именовать правообразующим юридическим составом. 
Для ответа на вопрос об основании правоотношения по найму служебного жилого помещения необходимо определить, существуют ли обособленно организационное (учетное) правоотношение, которое принято выделять в отношениях по социальному найму жилых помещений, и материальное правоотношение найма служебного жилого помещения. Если ответить на этот вопрос утвердительно, то для каждого из таких правоотношений следует также выделять свое юридико-фактическое основание. При отрицательном ответе достаточно констатировать, что в основании возникновения правоотношения по служебному найму лежит юридический состав: решение уполномоченного собственником органа об отнесении квартиры к служебным жилым помещениям и включении ее в специализированный жилищный фонд, решение о предоставлении служебного жилого помещения и непосредственно договор найма служебного жилого помещения.

Обоснованным выделение организационного (учетного) правоотношения будет в том случае, если его существование будет одним из обязательных условий действительности заключаемого впоследствии договора найма жилого помещения. На это обстоятельство применительно к отношениям по социальному найму указывал М.В. Бандо [2, с. 17], что вполне справедливо и для отношений по найму служебных жилых помещений.

Если обратиться к разъяснениям, данным в пункте 41 Постановления Пленума Верховного Суда РФ от 02 июля 2009 года № 14 «О некоторых вопросах, возникших в судебной практике при применении Жилищного кодекса Российской Федерации» [20], очевидно, что судебная практика признает наличие организационного (учетного) правоотношения, поскольку действительность заключаемого договора служебного найма поставлена в зависимость от соблюдения порядка отнесения жилого помещения к специализированному жилищному фонду, а также соблюдения требований закона при его предоставлении с учетом требований о нуждаемости лица в служебном жилом помещении.

По мнению автора, в правообразующем юридическом составе отношений по служебному найму жилых помещений правильным 
будет выделение ни одного организационного (учетного) правоотношения, а трех самостоятельных правоотношений (элементов): административно-организационного; организационно-учетного и договорного. Административно-организационное правоотношение охватывает включение жилого помещения в состав специализированного жилищного фонда; организационно-учетное - учет нуждающихся в служебных жилых помещениях и принятие решения о предоставлении служебного жилого помещения; договорное - заключение, исполнение, изменение и прекращение договора найма.

Так, вопрос о включении квартиры в число служебных жилых помещений принимается исключительно органом, осуществляющим управление государственным или муниципальным жилищным фондом, на основании заявления собственника или иного лица, обладающего вещным правом в отношении соответствующего жилого помещения (пункты 12 и 13 Правил отнесения жилого помещения к специализированному жилищному фонду) [14]. Следовательно, сторонами правоотношения по включению жилого помещения в специализированный жилищный фонд выступают его собственник (уполномоченное собственником лицо) и орган, осуществляющий управление соответствующим жилищным фондом; гражданин стороной такого правоотношения не является. Результатом административно-организационного правоотношения выступает соответствующее решение уполномоченного органа.

В отличие от административно-организационного правоотношения стороной организационно-учетного правоотношения всегда выступает гражданин. Как уже указывалось автором выше, нуждаемость в служебном жилом помещении выступает одним из условий правосубъектной предпосылки. Однако такая предпосылка сама по себе не может повлечь предоставление лицу жилого помещения иначе как путем его волеизъявления о такой потребности; именно с волеизъявления гражданина относительно своей нуждаемости начинается движение организационно-учетного правоотношения.

Само волеизъявление производится лицом путем написания заявления с приложением необходимых документов на имя органа госу- 
дарственного власти или местного самоуправления (уполномоченного им лица), а равно иного лица, органа или созданной ими комиссии, которым законом (в широком смысле) предоставлено такое право [15], с просьбой о постановке на соответствующий учет. По результатам рассмотрения заявления уполномоченным лицом выносится решение о постановке на учет или об отказе в постановке на учет.

Следующим этапом организационно-учетного правоотношения выступает принятие решения о предоставлении гражданину служебного жилого помещения. Необходимо отметить, что такое решение может быть принято как органом государственной власти или местного самоуправления, так и иным лицом (к примеру, муниципальным унитарным предприятием), однако результатом завершения организационно-учетного правоотношения всегда выступает решение о предоставлении лицу конкретного жилого помещения.

Только после принятия решения о предоставлении лицу конкретного жилого помещения возможно заключение договора найма, который, в свою очередь, служит основанием для занятия жилого помещения (квартиры). Применительно к пониманию природы этого договора следует согласиться с О.Г. Алексеевой, указавшей, что договор найма специализированного жилого помещения (что в полной мере распространяется и на наем служебного жилого помещения) представляет собой одну из разновидностей единого договорного типа - договора найма жилого помещения [1, с. 10], т.е. является консенсуальным, срочным, возмездным, двусторонним; реализация прав и обязанностей нанимателя и наймодателя производится в рамках такого договора, иначе говоря, в рамках материального правоотношения служебного найма.

Подводя итоги, необходимо отметить, что возможность движения жилищного правоотношения найма служебного жилого помещения определяется единством материальной, нормативной и правосубъектной предпосылок. В свою очередь правосубъектная предпосылка характеризуется рядом условий, несоблюдение любого из которых исключает ее наличие и, как следствие, возможность для лица вступить в правоотношения по найму служебного жило- 
го помещения. Если же при предоставлении служебного жилого помещения было допущено нарушение условий правосубъектной предпосылки, занятие лицом квартиры не может быть признано законным; на такое лицо должна возлагаться обязанность по освобождению незаконно занимаемого жилого помещения. При этом отсутствие любого из условий правосубъектной предпосылки не исцеляется ни давностью проживания лица в служебном жилом помещении, ни тем, что наймодателю было известно об отсутствии такого условия при предоставлении служебного жилого помещения. Данное обстоятельство имеет практическое значение при разрешении вопроса о возможности применения сроков исковой давности относительно требований о выселении лиц, незаконно занимающих служебные жилые помещения.

Анализ правоотношения по найму служебного жилого помещения позволяет прийти к выводу о том, что его основание составляет правообразующий юридический состав, в котором подлежит выделению административно-организационное правоотношение, организационно-учетное правоотношение и непосредственно сам договор найма служебного жилого помещения. При этом дефект административно-организационного или организационно-учетного правоотношения влекут недействительность договора найма, поскольку нарушение требований закона на любой из стадий предоставления служебного жилого помещения не способно восстанавливаться путем достижения сторонами соглашения относительно его занятия и использования. Вместе с тем, нарушение закона в рамках административно-организационного правоотношения, динамика которого лежит вне воли гражданина, не исключает возможности применения принципа доброй совести к нанимателю служебного жилого помещения, при условии отсутствия нарушений в рамках организационно-учетного правоотношения с его стороны, а также наличия у него правосубъектной предпосылки. Это обстоятельство должно учитываться судами при разрешении споров о законности занятия гражданином служебного жилого помещения по искам органов местного самоуправления о выселении 
из служебного жилого помещения в связи с нарушением порядка включения квартиры в специализированный жилищный фонд.

При подготовке данной статьи каких-либо нарушений требований антикоррупционного законодательства, приводящих к возникновению конфликта интересов, не установлено. Подготовка и публикаџия настоящей статьи осуществляется исключительно за счет личных средств автора.

\section{Список литературы}

1. Алексеева О.Г. Жилищное правоотношение социального найма: Автореферат дис. канд-та юр. наук. Екатеринбург, 2006. 30 с.

2. Бандо М.В. Основания возникновения жилищных правоотношений социального найма жилого помещения: Автореферат дис. канд-та юр. наук. Екатеринбург, 2010. 27 с.

3. Данилова Е.С. К вопросу о предпосылках и основании возникновения организационного правоотношения социального найма // Вестник Волжского университета им. В.Н. Татищева (институт). 2013. № 2 (78). С. 17-24.

4. Ем В.С., Киселев А.В. О понятии служебного жилого помещения // Проблемы современной цивилистики: Сборник статей, посвященных памяти профессора С.М. Корнеева [Отв. ред. Е.А. Суханов, М.В. Телюкина]. М: Статут, 2013. 348 с.

5. Исаков В.Б. Фактический состав в механизме правового регулирования. Саратов: Изд-во Саратовского университета, 1980. 78 с.

6. Красавчиков О.А. Юридические факты в советском гражданском праве. М.: Государственное издательство юридической литературы, 1958. $182 \mathrm{c}$.

7. Красавчиков О.А. Советское гражданское право в 2-х томах. Том первый, издание третье, исправленное и дополненное / Под ред. О.А. Красавчикова. М.: Высшая школа, 1985. 544 с.

8. Крашенинников П.В. Жилищное право: 9-е издание, переработанное и дополненное. М.: Статут, 2016. 384 с.

9. Толстой Ю.К. К теории правоотношения. Ленинград, 1959. 88 с. 
10. Шипунова Е.А. Стадии динамики жилищного правоотношения по найму специализированного жилого помещения // Жилищное право. 2010. № 8. С. 91-106.

11. Якупова А.И. Назначение, предоставление, использование служебных жилых помещений // Жилищное право. 2007. № 5. С. 12-18.

12. Жилищный кодекс Российской Федерации от 29 декабря 2004 года № 188-Ф3 (в ред. от 28.12.2016) // Парламентская газета. № 7-8. 15.01.2005.

13. Федеральный закон от 27.05.1998 года № 76-ФЗ (в ред. от 22.11.2016) «О статусе военнослужащих» // Собрание законодательства РФ. № 22. 01.06.1998. ст. 2331.

14. Постановление Правительства РФ от 26 января 2006 № 42 (в ред. Постановления Правительства РФ от 18 июля 2016 № 689) // Собрание законодательства РФ. 06.02.2006. № 6. ст. 697.

15. Приказ Судебного департамента при Верховном Суде РФ от 07 июня 2012 года № 123 (ред. от 26.11.2014) «Об утверждении Положения о жилищной комиссии» // Бюллетень актов по судебной системе. № 2. февраль. 2016.

16. Гражданский кодекс РСФСР (утв. ВС РСФСР 11 июня 1964 года) // Ведомости ВС РСФСР. 1964. № 24. ст. 407.

17. Жилищный кодекс РСФСР (утв. ВС РСФСР от 24 июня 1983, в ред. от 18.01.1985) // Свод законов РСФСР. т. 3. с. 7.

18. Гражданский кодекс РСФСР (утв. Постановлением ВЦИК РСФСР от 11 ноября 1922 года) // Известия ВЦИК. № 256. 12.11.1922.

19. Определение Конституционного Суда РФ от 25.12.2003 года № 453-О «Об отказе в принятии к рассмотрению жалобы администрации муниципального образования «Сертолово» Ленинградской области на нарушение конституционных прав и свобод пунктом 5 статьи 15 Федерального закона «О статусе военнослужащих» // Вестник Конституционного Суда РФ. 2004. № 3.

20. Постановление Пленума Верховного Суда РФ от 02 июля 2009 года № 14 «О некоторых вопросах, возникших в судебной практике при применении Жилищного кодекса Российской Федерации» // Российская газета. № 123. 08.07.2009. 
21.Апелляционное определение Московского областного суда от 13.05.2015 по делу № 33-10797/2015; Постановление Президиума Новосибирского областного суда от 19.08.2016 по делу № 44г-80/2016 // СПС «Консультант плюс» (по состоянию на 09.01.2016).

\section{References}

1. Alekseeva O.G. Zhilishhnoe pravootnoshenie social'nogo najma [Housing legal relationship of social hiring]. Ekaterinburg, 2006, $30 \mathrm{p}$.

2. Bando M.V. Osnovanija vozniknovenija zhilishhnyh pravootnoshenij social'nogo najma zhilogo pomeshhenija [Grounds for the emergence of housing legal relations of social hiring of living quarters]. Ekaterinburg, 2010, 27 p.

3. Danilova E.S. Vestnik Volzhskogo universiteta im. V.N. Tatishheva (institut), 2013, № 2 (78), pp. 17-24.

4. Em V.S., Kiselev A.V. Problemy sovremennoj civilistiki: Sbornik statej, posvjashhennyh pamjati professora S.M. Korneeva [Problems of modern civilization: Collected papers dedicated to the memory of Professor S.M. Korneev]/ E.A. Suhanov, M.V. Teljukina (ed.). M: Statut, 2013, 348 p.

5. Isakov V.B. Fakticheskij sostav v mehanizme pravovogo regulirovanija [Actual composition in the mechanism of legal regulation]. Saratov: Izd-vo Saratovskogo universiteta, 1980, 78 p.

6. Krasavchikov O.A. Juridicheskie fakty $v$ sovetskom grazhdanskom prave [Legal facts in Soviet civil law]. M.: Gosudarstvennoe izdatel'stvo juridicheskoj literatury, 1958, $182 \mathrm{p}$.

7. Krasavchikov O.A. Sovetskoe grazhdanskoe pravo v 2-h tomah [Soviet civil law in 2 volumes], V. 1. / O.A. Krasavchikov (ed.). M.: Vysshaja shkola, 1985, $544 \mathrm{p}$.

8. Krasheninnikov P.V. Zhilishhnoe pravo [Housing law]. M.: Statut, 2016, $384 \mathrm{p}$.

9. Tolstoj Ju.K. K teorii pravootnoshenija [To the theory of legal relationship]. Leningrad, 1959, 88 p.

10. Shipunova E.A. Zhilishhnoe pravo, 2010, № 8, pp. 91-106.

11. Jakupova A.I. Zhilishhnoe pravo, 2007, № 5, pp. 12-18. 
12.Zhilishhnyj kodeks Rossijskoj Federacii ot 29 dekabrja 2004 goda № 188-FZ (v red. ot 28.12.2016) [The Housing Code of the Russian Federation of December 29, 2004, No. 188-FZ (as amended on December 28, 2016)]. Parlamentskaja gazeta, № 7-8, 15.01.2005.

13. Federal'nyj zakon ot 27.05.1998 goda № 76-FZ (v red. ot 22.11.2016) «O statuse voennosluzhashhih» [Federal Law of 27.05.1998 № 76-FZ (as amended on November 22, 2016) "On the status of servicemen"]. Sobranie zakonodatel'stva RF, № 22, 01.06.1998, st. 2331.

14. Postanovlenie Pravitel'stva RF ot 26 janvarja 2006 № 42 (v red. Postanovlenija Pravitel'stva RF ot 18 ijulja 2016 № 689) [Resolution of the Government of the Russian Federation of January 26, 2006 No. 42 (in the edition of the Resolution of the Government of the Russian Federation of July 18, 2016 No. 689)]. Sobranie zakonodatel'stva RF, 06.02.2006, № 6, st. 697 .

15. Prikaz Sudebnogo departamenta pri Verhovnom Sude RF ot 07 ijunja 2012 goda № 123 (red. ot 26.11.2014) «Ob utverzhdenii Polozhenija o zhilishhnoj komissii» [Order of the Judicial Department under the Supreme Court of the Russian Federation of June 7, 2012 No. 123 (Edited on November 26, 2014) "On approval of the Regulations on the Housing Commission”]. Bjulleten’aktov po sudebnoj sisteme, № 2, 2016.

16. Grazhdanskij kodeks RSFSR (utv. VS RSFSR 11 ijunja 1964 goda) [Civil Code of the RSFSR (approved by the Supreme Soviet of the RSFSR June 11, 1964)]. Vedomosti VS RSFSR, 1964, № 24, st. 407.

17.Zhilishhnyj kodeks RSFSR (utv. VS RSFSR ot 24 ijunja 1983, v red. ot 18.01.1985) [Housing Code of the RSFSR (approved by the Supreme Soviet of the RSFSR of June 24, 1983, as amended on 18.01.1985)]. Svod zakonov RSFSR, t. 3, s. 7.

18. Grazhdanskij kodeks RSFSR (utv. Postanovleniem VCIK RSFSR ot 11 nojabrja 1922 goda) [Civil Code of the RSFSR (approved by the Resolution of the All-Russian Central Executive Committee of the RSFSR of November 11, 1922)]. Izvestija VCIK, № 256, 12.11.1922.

19. Opredelenie Konstitucionnogo Suda RF ot 25.12.2003 goda № 453-O «Ob otkaze v prinjatii k rassmotreniju zhaloby administracii municipal'nogo obrazovanija «Sertolovo» Leningradskoj oblasti na narushenie 
konstitucionnyh prav i svobod punktom 5 stat'i 15 Federal'nogo zakona «O statuse voennosluzhashhih» [Definition of the Constitutional Court of the Russian Federation No. 453-O of 25.12.2003 "On refusal to accept the complaint of the administration of the Sertolovo Municipality of the Leningrad Region for violation of constitutional rights and freedoms by paragraph 5 of Article 15 of the Federal Law" On the Status of Servicemen"]. Vestnik Konstitucionnogo Suda RF, 2004, № 3.

20. Postanovlenie Plenuma Verhovnogo Suda RF ot 02 ijulja 2009 goda № 14 «O nekotoryh voprosah, voznikshih v sudebnoj praktike pri primenenii Zhilishhnogo kodeksa Rossijskoj Federacii» [Resolution of the Plenum of the Supreme Court of the Russian Federation of July 2, 2009 No. 14 "On some issues that arose in judicial practice when applying the Housing Code of the Russian Federation”]. Rossijskaja gazeta, № 123, 08.07.2009.

21. Apelljacionnoe opredelenie Moskovskogo oblastnogo suda ot 13.05.2015 po delu № 33-10797/2015; Postanovlenie Prezidiuma Novosibirskogo oblastnogo suda ot 19.08.2016 po delu № 44g-80/2016 [Appeal of the Moscow Regional Court of 13.05.2015 in case No. 33-10797 / 2015; Decree of the Presidium of the Novosibirsk Regional Court of August 19, 2016 in the case No. 44g-80/2016]. Konsul'tant pljus (09.01.2016).

\section{ДАННЫЕ ОБ АВТОРЕ}

\section{Папушина Наталья Юрьевна, судья}

Новосибирский областной суд

ул. Писарева, 35 г. Новосибирск, Новосибирская область, 630091, Российская Федерачия

papushinanatalya@yandex.ru

\section{DATA ABOUT THE AUTHOR}

\section{Papushina Natalya Yur'evna, Judge}

Novosibirsk Regional Court

35, Pisarev Str., Novosibirsk, Novosibirsk region, 630091, Russian Federation

papushinanatalya@yandex.ru

SPIN-code: 2592-6960 